\title{
Injury to Stomach with Open Wound into Cavity
}

National Cancer Institute

\section{Source}

National Cancer Institute. Injury to Stomach with Open Wound into Cavity. NCI

Thesaurus. Code C35238.

Trauma to the stomach associated with a break in the tissue that extends into the abdominal cavity. 